\title{
Development and Evaluation of Goat Milk Tablet Using Dry Granulation Techniques for Nutraceutical Purposes
}

\author{
${ }^{1}$ Aminuddin Azfar, ${ }^{2}$ Mohd Akmal Azhar* \\ ${ }^{1,2}$ Faculty of Engineering Technology, University Malaysia Pahang, 26300, Kuantan, Pahang, Malaysia
}

\begin{abstract}
There are several problems for the school children to take the pure milk especially the goat milk every day because of the unpleasant taste and smell of the goat milk are not so good. Besides, the pure milk has a short life time. It is difficult to store the goat milk in a long period of time at room temperature. The solution for this problem is change the goat milk from liquid form into the chewable milk tablet that can be easily consume by the school children. Goat milk in the form of tablet formulation will increase the shelf life of the product. Therefore, the chewable goat milk tablet can be stored in a long period of time, convenience, and suitable for distribution to remote areas. In this project, the focusing was more into the optimization of the weight adjustment of the tableting machine before and after the dry granulation to form good chewable tablet. The pre-evaluation had been done for the goat milk powder and granule after dry granulation process. It can be concluded that goat milk tablet can be an alternative to the pure goat milk. The poorly flowing properties of goat milk powder can be improved by using dry granulation techniques. Based on this study, F4D shows the best setting to produce the goat milk tablet using dry granulation technique. F4D successfully improved the flow ability and compressibility of goat milk tablet. It also produce the best goat milk tablet as it possess uniformity of weight, low friability and good hardness
\end{abstract}

Index Terms- Gold milk, dry granulation, tablet dosage, oral forms, nutraceutical

\section{INTRODUCTION}

Milk is very important for the children because during this age, they need more nutritious food as their cells and organs growth. It seems to be a problem for the children to take milk every day because of their full scheduled and lack of parents supervision. Research study state that the normal children will have much greater consumption of the fat and carbohydrate which contain in the milk as compared to an adult [1]. There are scientific investigation by the FDA that $15 \%-20 \%$ of the energy is come from protein and it produce almost $800-1000 \mathrm{kcal}$ [2]. In Malaysia, there are a lot of skim milk or powder milk produced by the manufacturer and marketed in the pharmacy and supermarket. For the different type of the milk powder, the nutritive value and protein content contain in it also will be different. Therefore, it is important to choose suitable milk formulation for the children consumption. In Malaysia, the cow's and goat's milk are the easiest milk to be obtained in the market. However, the demand of the goat milk nowadays has becoming a trending because of their advantages in term of nutrient and digestion [3]. Goat milk possesses unique properties, which distinguish it from cow milk and make it a valuable alternative in the case of digestion problems [4].

There are several problems for the school children to take the pure milk especially the goat milk every day because of the unpleasant taste and smell of the goat milk are not so good. Besides, the pure milk has a short life time. It is difficult to store the goat milk in a long period of time at room temperature. It must be stored in the refrigerator and this become a problem for the rural children because some of them do not have a refrigerator at their home. Moreover, it might be impossible for them milking the goat milk every day. It is a challenge for many children and their families coping with school demands, after school activities, and work schedules.

The solution for this problem is change the goat milk from liquid form into the chewable milk tablet that can be easily consume by the school children. If the goat milk is formulated into tablet, the shelf life of the milk will be increased. So the chewable goat milk tablet can be stored in a long period of time, convenience, and suitable for distribution to remote areas. Besides, the tablet is easier to store as compared to the fresh milk which only need a room temperature to store it. Therefore, there is no more excuses for the school children to take milk every day. This milk tablet is easy to consume, easy to store, and the taste is better than fresh milk. 
The milk tablet is one of the nutraceutical product that can provide high nutritive value which is very important for the school children [5]. The pure milk powder has very poor flow property, therefore the formulation need to be optimize with addition of several excipient by using the dry granulation method. This method is more preferable because the property of the goat milk powder and excipient are sensitive to moisture condition [6], thus it helps to increase the size of granules within powders, making it easier to form them into tablets.

A study was develop by [7] to produce milk tablet to enhance more diary consumption as well as to improve nutritional status for Thailand children in rural area. That study also claimed that sensory acceptability is important in order for children to consume protein milk tablet. This project is aimed to develop and evaluate the chewable goat milk tablet as a supplementary food for children.

In this project, the focusing was more into optimize the weight adjustment of the tableting machine before and after the dry granulation to form good chewable tablet. Goat milk tablet can probably be an interesting alternative to produce because it is easy to consume and can bring to everywhere. Moreover, the goat odor can decrease by adding various flavoring agents. It is important to improvise the taste and odor of the goat milk before it is compressed into the milk tablet, so it will have attractive value for children.

\section{METHODOLOGY}

\subsection{Formulation of Goat Milk Tablet}

The composition of the goat milk tablets per $500 \mathrm{mg}$ consist of whole milk powder (55\%) as a main ingredients, microcrystalline cellulose (15\%) as a disintegrant, polyvinylpyrrolidone (4\%) as a binder, talc $(10 \%)$ as a glidant, sucrose $(15 \%)$ as a sweetener and magnesium stearate $(1 \%)$ are presented in table 1. This formulation was from from the previous study [8].

Table 1: List of excipient in $500 \mathrm{mg}$ tablet

\begin{tabular}{|c|c|c|}
\hline Excipients: & $\begin{array}{c}\text { Percentage use in } \\
500 \mathrm{mg} \text { milk tablets: }\end{array}$ & $\begin{array}{c}\text { Weight of the } \\
\text { excipients in 500mg: }\end{array}$ \\
\hline Whole milk powder & $55 \%$ & $275 \mathrm{mg}$ \\
\hline Microcrystallline cellulose & $15 \%$ & $75 \mathrm{mg}$ \\
\hline Polyvinylpyrrolidone & $4 \%$ & $20 \mathrm{mg}$ \\
\hline Sucrose & $15 \%$ & $75 \mathrm{mg}$ \\
\hline Talc & $10 \%$ & $50 \mathrm{mg}$ \\
\hline Magnesium stearate & $1 \%$ & $5 \mathrm{mg}$ \\
\hline
\end{tabular}

\subsection{Primary Mixing}

All ingredients were weighed accurately according to each formulation as shown in Table 1 by using weighing balance. After that, the ingredients were passed separately through a sieve. All ingredients except magnesium stearate were mixed thoroughly using Shakti Double Cone Blender for 15 minutes. The speed of the double cone blender were set at $35 \mathrm{rpm}$. After that, mixed powder were then kept into a polybag before determining the powder characteristic evaluation.

\subsection{Primary Compressing (slugging)}

The well mixed excipients will be compressed to become a slug by using the rotary tableting machine from Shakti Pharmatech as a slug. The tableting machine was set for 18,21,24,27 and 30 unit as shown in table 2 
Table 2: weight adjustment of primary compression

\begin{tabular}{|c|c|}
\hline No of batch: & Weight adjustment (unit): \\
\hline Batch F1 & 18 \\
\hline Batch F2 & 21 \\
\hline Batch F3 & 24 \\
\hline Batch F4 & 27 \\
\hline Batch F5 & 30 \\
\hline
\end{tabular}

\subsection{Milling Process}

The slug with a diameter of $10 \mathrm{~mm}$ will be crush into small granules using the blending machine Brand UAE model UEWD-100. The tablet will be feed into the feeding hopper of blending machine and the granule produced will be used for final compression.

\subsection{Secondary Mixing}

Magnesium stearate were added to the formulation granules and mixed again using double cone blender at $35 \mathrm{rpm}$ for 15 minutes.

\subsection{Final Compressing}

The granules will be compressed using the rotary tableting machine from Shakti Pharmatech. The tableting machine is set for $40 \mathrm{KN}$ force with 5 different weight adjustment and $10 \mathrm{~mm}$ diameter of tablet mould as presented in table 3 . The tablet will be collected for the further evaluation.

Table 3: weight adjustment for final compression

\begin{tabular}{|c|c|c|c|c|c|}
\hline Batch 1 & Batch 2 & Batch 3 & Batch 4 & Batch 5 & Weight adjustment (Unit) \\
\hline F1A & F2A & F3A & F4A & F5A & 18 \\
\hline F1B & F2B & F3B & F4B & F5B & 21 \\
\hline F1C & F2C & F3C & F4C & F5C & 24 \\
\hline F1D & F2D & F3D & F4D & F5D & 27 \\
\hline F1E & F2E & F3E & F4E & F5E & 30 \\
\hline
\end{tabular}

\subsection{Evaluation of goat milk powder characteristic}

The physical properties of the tablets production was evaluated for the uniformity of weight, thickness, hardness and friability.

\subsection{Weight variation testing}

The tablet weight variation was carried out according to [9]. 20 tablets were weight separately. The average weight of 20 tablets was calculated. The percentage difference of each tablet was also calculated and compared to the limit set by USP.

\subsection{Thickness and hardness of tablet}

The thickness and the hardness of the tablet were measured by using Electrolab harness tester. 20 tablets were test individually for each formulation and repeated for other formulation. 


\subsection{Friability of the tablet}

The fribilator brand Electrolab was used to determine the friability. 20 tablets were weight for its initial weight and place into the friabilator. The tablet were rotated in the friabilator for $25 \mathrm{rpm}$ for 100 revolution. Pre-weight tablet were dusted and reweight. Friability of the tablet was calculated according to the requirement set by [9].

\subsection{Bulk density, tapped density and compressibility index}

Bulk density was measure using Electrolab tap density tester. The powder blend was measure by slowly pouring $100 \mathrm{~g}$ of the powder blends into $250 \mathrm{ml}$ measuring cylinder on that machine. Bulk density was calculated by dividing the sample weight with its volume. Tapped density also was measured by using Electrolab tap density tester. $100 \mathrm{~g}$ powder blends was slowly poured into the $250 \mathrm{ml}$ measuring cylinder on that machine. The sample was mechanically tapped at 10, 500 and 1250 times. Tapped density was calculated by dividing the sample weight by its final volume at 1250 times according to the requirement set by [9].

\subsection{Protein content}

The protein content of the milk tablet and powder was evaluate using the Bradford method [10].

\section{RESULTS AND DISCUSSIONS}

For the powder characteristic, the result from the tab density tester, compressibility index and flow property for the granule produced before (batch F) and after slugging and milling process was shown in table 4. Flow property after slugging and milling process (batch F1-F5) shown better result compared to pure milk powder (batch F). This is because in the dry granulation method, the particles were brought together very close by mechanical pressure and they are bonded with short-range van der Waals and electrostatic forces [6]. There are several reasons of using dry granulation method including to prevent segregation, improve the content uniformity of low concentration component such as the sweetener and lubricant, reduce dust of the powder, increase particle density and to improve powder flow property. Therefore dry granulation was selected for the formulation of the goat milk tablet because the bad powder flow property can be improve after slugging process. Besides, this method can maintain the moisture content of the excipient without exposed it to the water. The granule from batch F4 was selected as the best based on the scale of flow ability provided by USP $<1174>$ powder flow by comparing the compressibility index and hausner ratio. Batch F4 was used to optimize the physical adjustment for final compression.

\section{Table 4: Tab density testing result}

\begin{tabular}{|c|c|c|c|}
\hline Batch & Compressibility index (\%) & Hausner ratio & Flow property \\
\hline F & 31.90 & 1.47 & Very poor \\
\hline F1 & 27.78 & 1.39 & Poor \\
\hline F2 & 25.28 & 1.34 & Poor \\
\hline F3 & 24.10 & 1.32 & Poor \\
\hline F4 & 20.00 & 1.25 & Fair \\
\hline F5 & 22.08 & 1.28 & Passable \\
\hline
\end{tabular}

The property of the powder will affect the formulation of milk tablet. The pure goat milk powder has very poor flow properties become impossible to compress the goat milk alone to form a tablet. Moreover, the powder will stacked on the hopper and die of the rotary tableting machine. Therefore 
the excipient must be added to improve the physical property of milk powder [11]. Sucrose has been used as a sweetening agent because it does not harmful to children and also increase the hardness and acceptability of the milk tablet. Researcher [12] stated that microcrytalline cellulose was among the best disintegrant and it has been used a disintegrant for this formulation. Talc have been used as a glidant because the improvement of the flow property in the dry granulation process [12].

The physical appearance of goat milk tablets which obtained by dry granulation method can be seen in figure 1 that were yellowish white with shiny and smooth surface.

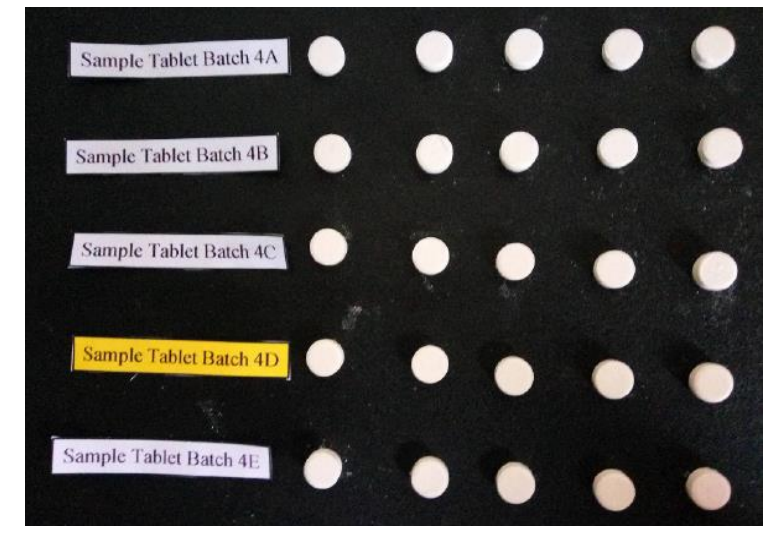

Figure 1: Goat milk tablet for batch F4

The post-compression evaluation result of final compression for batch F4 was shown in table 5 .

Table 5: Post-compression evaluation result

\begin{tabular}{|c|c|c|c|c|}
\hline Batch & $\begin{array}{c}\text { Weight } \\
\text { Adjustment (unit) }\end{array}$ & $\begin{array}{c}\text { Weight } \\
\text { variation }(\%)\end{array}$ & $\begin{array}{c}\text { Hardness } \\
(\mathrm{kp})\end{array}$ & $\begin{array}{c}\text { Friability } \\
(\%)\end{array}$ \\
\hline F4A & 18 & 6.5 & 2.27 & 6.06 \\
\hline F4B & 21 & 5.7 & 4.97 & 0.56 \\
\hline F4C & 24 & 4.5 & 5.75 & 0.52 \\
\hline F4D & 27 & 2.7 & 6.33 & 0.54 \\
\hline F4E & 30 & 4.9 & 6.18 & 0.64 \\
\hline
\end{tabular}

From the result obtained in this study, the F4C, F4D and F4E were passed for the weight variation test. Among these three batches, F4D shows the best result for weight variation test. According to USP (US Pharmacopoeia), the tablet that has weight more than $324 \mathrm{mg}$ must have percentage different less than $5 \%$ or else the tablet cannot be marketed. This is because the variety of the weight can affect the tablet content.

Hardness is one of the important criteria for chewable tablets. This tablet was targeted for school children, therefore the hardness of the tablet cannot be too high resulting hard to consume or too low resulting poor physical properties of the tablet. According to the [7], the hardness of tablet between $3 \mathrm{kp}-7 \mathrm{kp}$ was preferred by children. Thus, F4B, F4C, F4D and F4E produced the best hardness for tablet.

Different weight adjustment of lower punch showed different amount of hardness. The higher the weight adjustment the higher the reading of hardness. The friability of the tablet also related with the hardness of the tablet. If the tablet have low hardness, the friability of the tablet will be high. This is because since the crushing strength of the tablet are low, it is much easier to break down into small pieces. According to USP, the friability is acceptable if it is less than $1 \%$. Based on the result, F4B, F4C, F4D and F4E pass the acceptable limit of friability.

The result of protein content comparison between pure goat milk powder and goat milk tablet was shown in table 6. 
Table 6: Protein content in pure goat milk powder and goat milk tablet

\begin{tabular}{|c|c|c|}
\hline Sample & Protein content $(\mathrm{mg})$ & Protein content (\%) \\
\hline $415.4 \mathrm{mg}$ of pure goat milk powder & 152.5 & 36.7 \\
\hline $415.4 \mathrm{mg}$ of goat milk tablet & 38.0 & 9.2 \\
\hline
\end{tabular}

Based on the table 6 , the protein content of the goat milk tablet was reduced by $27.5 \%$ because of several factor. Firstly because of mechanical factor where during the compression process and breakdown of tablet into small granules, the protein content might be denatured. Secondly, the protein can be denatured when the goat milk powder was exposed to heat during the mixing process. Thirdly, the composition of goat milk powder used in this formulation was only $55 \%$ from the total $100 \%$. Therefore, that were the reasons why the amount of protein content is smaller as compared to the pure milk powder sample.

\section{CONCLUSIONS}

The need of the goat milk for the school children has led to the idea of producing goat milk tablets. Therefore, the researcher come out with various idea of formulation of goat milk with different dosage forms. From this study, it can be concluded that goat milk tablet can be an alternative to the pure goat milk. The poorly flowing properties of goat milk powder can be improved by using dry granulation techniques. Weight adjustment of the lower punch also plays important roles in order to obtain good physical properties of the tablet. Based on this study, F4D shows the best setting to produce the goat milk tablet using dry granulation technique. This batch successfully improved the flow ability and compressibility of goat milk tablet. This batch also produce the best goat milk tablet as it possess uniformity of weight, low friability and good hardness.

\section{ACKNOWLEDGEMENTS}

We thank the staff and fellow researchers at the Faculty of Engineering Technology, Universiti Malaysia Pahang. This project was funded by UMP Grant RDU 1403146.

\section{REFERENCES}

[1] H. Batchelor and H. K., "Influence of Food on Paediatric Gastrointestinal Drug Absorption Following Oral Administration: A Review," Children, vol. 2, no. 2, pp. 244-271, Jun. 2015.

[2] CDER, "Guidance for Industry - Food-Effect Bioavailability and Fed Bioequivalence Studies," Federeal Regist. Doc., no. ., 2002.

[3] M. A. Azhar and N. Salim, "Isolation and Molecular Characterization of Local Goat Milk Casein for Nutraceutical Value," MATEC Web Conf., vol. 97, p. 1084, Feb. 2017.

[4] F. Yangilar, "As a Potentially Functional Food: Goats' Milk and Products," J. Food Nutr. Res., vol. 1, no. 4, pp. 68-81, 2013.

[5] D. B. Kapadiya, D. B. Prajapati, A. K. Jain, B. M. Mehta, V. B. Darji, and K. D. Aparnathi, "Comparison of Surti goat milk with cow and buffalo milk for gross composition, nitrogen distribution, and selected minerals content.," Vet. world, vol. 9, no. 7, pp. 710-6, Jul. 2016.

[6] P. Kulinowski, K. Woyna-Orlewicz, J. Obrał, G.-M. Rappen, D. Haznar-Garbacz, W. P. Węglarz, R. Jachowicz, G. Wyszogrodzka, J. Klaja, and P. P. Dorożyński, "Multimodal approach to characterization of hydrophilic matrices manufactured by wet and dry granulation or direct compression methods," Int. J. 
INTERNATIONAL JOURNAL OF ENGINEERING TECHNOLOGY AND SCIENCES (IJETS) Vol.7 (1) June 2017 DOI: http://dx.doi.org/10.15282/ijets.7.2017.1.2.1064

Pharm., vol. 499, no. 1-2, pp. 263-270, Feb. 2016.

[7] M. Natvaratat, P. Chompreeda, V. Haruthaithanasan, and H. Rimkeeree, "Optimization of Supplementary Protein Milk Tablet Formulation for Rural School Children under Her Royal Highness Princess Maha Chakri Sirindhorn’s Project,” vol. 739, pp. 733-739, 2007.

[8] N. I. Iyah, "Development \& evaluation of goat milk tablet by using direct compression method," Bachelor enginering Technol., 2016.

[9] USP, "U.S. Pharmacopoeia-National Formulary [USP 38 NF 33]," Rockville, Md United States Pharmacopeial Conv., vol. volume 1, 2015.

[10] N. J. Kruger, "The Bradford Method for Protein Quantitation," in The Protein Protocols Handbook, Totowa, NJ: Humana Press, 1996, pp. 15-20.

[11] S. Butani, H. Shah, and D. Parikh, "FORMULATION DEVELOPMENT\& OPTIMIZATION OF MILK DISSOLVING TABLETS AS NOVEL PEDIATRIC DOSAGE FORM,” Int. J. DRUG Formul. Res. Formul., no. 2, pp. 84-96, 2014.

[12] B. Selvaraj, P. Shanmugapandiyan, and P. Shanmugapandiyan, "FORMULATION AND DEVELOPMENT OF TRAMODOL HYDROCHLORIDE EXTENDED RELEASE TABLETS,” $J$. Drug Deliv. Ther., vol. 3, no. 4, pp. 72-78, Jul. 2013. 